\title{
Remarkably high ingestion ratio of acidic food in juvenile marble goby, Oxyeleotris marmorata
}

\author{
Chui-Fen Teoh $\cdot$ Leong-Seng Lim 1 - Gunzo Kawamura
}

Received: 14 April 2017/Accepted: 6 December 2017/Published online: 11 December 2017

(C) The Author(s) 2017. This article is an open access publication

\begin{abstract}
Behavioral test was conducted to determine the level of food $\mathrm{pH}$ which was preferable by the juvenile marble goby, Oxyeleotris marmorata (50 individuals or replicates; total length 6.6-7.0 cm) using agar gel pellets. Eight $\mathrm{pH}$ levels of agar gel pellets were prepared $(\mathrm{pH} 2.4,3.0,3.2,3.4,4.1,4.9,5.1$, and the pure agar gel pellet without $\mathrm{pH}$ modification- $\mathrm{pH}$ 5.9). The ingestion ratio for each $\mathrm{pH}$ treatment of agar gel pellet was calculated, and the binary data (ingested or rejected) was analyzed using binomial test. Negative relationship was found between the ingestion ratio and $\mathrm{pH}$ level of the agar gel pellets. The highest ingestion ratio was found in the agar gel pellet with $\mathrm{pH} 2.4$ (ingestion ratio, 94\%), following by $\mathrm{pH} 3(85 \%)$, pH 3.2 (3\% agar gel powder; 65\%), pH 3.2 (2\% agar gel powder; 58\%), pH 3.4 (24\%), pH $4.1(6 \%), \mathrm{pH} 4.9$ (6\%), pH 5.1 (6\%), and $\mathrm{pH} 5.9(2 \%)$. The ingestion ratio of $\mathrm{pH} 2.4$ agar gel pellet was significantly higher $(P<0.05)$ than that in the other treatments except that of $\mathrm{pH}$ 3.0. These results confirmed the taste preference of $O$. marmorata for acidic foods, and the most preferred was the one with $\mathrm{pH}$ 2.4-3.0.
\end{abstract}

Keywords Taste preference $\cdot$ Feeding $\cdot$ Dietary $\mathrm{pH} \cdot$ Behavior $\cdot$ Weaning $\cdot$ Oxyeleotris marmoratus

\begin{tabular}{ll}
\multicolumn{2}{l}{ Abbreviations } \\
FT pellet & For-training pellet \\
PAG pellet & Pure agar gel pellet \\
TS pellet & Test substance pellet \\
$\mathrm{HCl}$ & Hydrochloric acid \\
$\mathrm{NaCl}$ & Sodium chloride \\
$\mathrm{CaCl}$ & Calcium chloride \\
$\mathrm{CI}$ & Confidence interval
\end{tabular}

\section{Introduction}

Marble goby, Oxyeleotris marmorata is a freshwater fish species with high commercial value, especially in Southeast Asia (Asia-Pacific Fishery Commission 2014). It is also a popular candidate for aquaculture in many Southeast Asian countries including Malaysia, Thailand, and Vietnam (Cheah et al. 1994; Lin and

C.-F. Teoh · L.-S. Lim $(\bowtie) \cdot$ G. Kawamura

Borneo Marine Research Institute, Universiti Malaysia Sabah, Jalan UMS, 88400 Kota Kinabalu, Sabah, Malaysia

e-mail: leongsen@ums.edu.my 
Kaewpaitoon 2000; Luong et al. 2005). However, it was reported that this fish generally rejects formulated feeds (Rojtinnakorn et al. 2012) and this results in its poor growth and survival. In addition to that, information on the nutritional requirement of $O$. marmorata is still limited up-to-date (Cheah et al. 1994; Lin and Kaewpaitoon 2000; Yong et al. 2015), and there is still no compounded feed commercially available for this fish. For these reasons, there is a need to find way to improve the acceptability of formulated feeds to $O$. marmorata. In the previous studies, amino acids mixture and nucleotides were reported as the suitable feeding stimulant through behavioural assays (Lim et al. 2015, 2016, 2017) and dietary supplementation of these taste substances can be practiced to improve the weaning of $O$. marmorata (Lai et al. in press). However, amino acid mixture and nucleotides are expensive and supplementation of these taste substances in the practical diet for $O$. marmorata may not be cost-effective.

According to Kasumyan and Døving (2003), fish has sensation to sour taste and its preference for food acidity is species-specific. This fact provides us the rationale to determine the possibility of improving the acceptability of formulated feeds to $O$. marmorata by manipulating the feed's $\mathrm{pH}$ to the fish preferable level, which is also a simple and cheaper way (by means of adding in acid) than the dietary supplementation of feeding stimulant mentioned earlier. However, information on the taste preference of $O$. marmorata for feeds with different $\mathrm{pH}$ levels and the level of $\mathrm{pH}$ in the feed most preferred by $O$. marmorata is unknown. Therefore, the present study was conducted to determine the $\mathrm{pH}$ level of food which is preferred by the $O$. marmorata juveniles.

\section{Methods}

Preparation of agar gel pellets

In this study, behavioral test was conducted and agar gel pellet was used as the food medium in the test. The types and composition of agar gel pellet prepared for the test are shown in Table 1. Two types of agar gel pellets were prepared: (1) the For-Training (FT) pellet that contained the extract of the commercial pellet, size $3.1 \mathrm{~mm}$ (Otohime, EP3 type, Nisshin Co., Tokyo, Japan), and (2) the Test Substance (TS) pellets which contained distilled water and different amounts of diluted or non-diluted hydrochloric acid- $\mathrm{HCl}(37 \%, 16 \mathrm{M}$, MERCK, NJ, USA). The pure agar gel (PAG) pellet that contained only distilled water (without $\mathrm{HCl}$ ) was used as the negative control in the present study. In general, all agar gel pellets were prepared by dissolving

Table 1 Types of agar gel pellet prepared for the behavioral test in the present study with its ingredients and compositions

\begin{tabular}{|c|c|c|c|c|c|}
\hline & $\begin{array}{l}\text { Distilled } \\
\text { water }\end{array}$ & $\begin{array}{l}\text { Otohime } \\
\text { extract }\end{array}$ & $\begin{array}{l}\text { Agar gel } \\
\text { powder }\end{array}$ & $\begin{array}{l}\text { Red food } \\
\text { dye }^{b}\end{array}$ & $\begin{array}{l}\mathrm{HCl}^{\mathrm{c}} \\
\text { (molarity) }\end{array}$ \\
\hline \multicolumn{6}{|l|}{ Treatments } \\
\hline For-training $(\mathrm{FT})$ pellet- $-\mathrm{pH} 5.6$ & N/A & $50 \mathrm{ml}$ & $1.0 \mathrm{~g}$ & $0.05 \mathrm{~g}$ & N/A \\
\hline \multicolumn{6}{|l|}{ Test-substance (TS) pellets } \\
\hline $\begin{array}{l}\text { (1) Pure agar gel (PAG) pellet- }-\mathrm{pH} \\
5.9\end{array}$ & $50 \mathrm{ml}$ & N/A & $1.0 \mathrm{~g}$ & $0.05 \mathrm{~g}$ & N/A \\
\hline (2) $2 \%$ agar powder-pH 5.1 & $50 \mathrm{ml}$ & N/A & $1.0 \mathrm{~g}$ & $0.05 \mathrm{~g}$ & $10 \mu \mathrm{l}(0.1 \mathrm{M})$ \\
\hline (3) $2 \%$ agar powder $-\mathrm{pH} 4.9$ & $50 \mathrm{ml}$ & N/A & $1.0 \mathrm{~g}$ & $0.05 \mathrm{~g}$ & $10 \mu \mathrm{l}(1 \mathrm{M})$ \\
\hline (4) $2 \%$ agar powder- $-\mathrm{pH} 4.1$ & $50 \mathrm{ml}$ & N/A & $1.0 \mathrm{~g}$ & $0.05 \mathrm{~g}$ & $10 \mu \mathrm{l}(3 \mathrm{M})$ \\
\hline (5) $2 \%$ agar powder- $-\mathrm{pH} 3.4$ & $50 \mathrm{ml}$ & N/A & $1.0 \mathrm{~g}$ & $0.05 \mathrm{~g}$ & $10 \mu \mathrm{l}(16 \mathrm{M})$ \\
\hline (6) $2 \%$ agar powder-pH 3.2 & $50 \mathrm{ml}$ & N/A & $1.0 \mathrm{~g}$ & $0.05 \mathrm{~g}$ & $18 \mu \mathrm{l}(12 \mathrm{M})$ \\
\hline (7) $3 \%$ agar powder $-\mathrm{pH} 3.2$ & $50 \mathrm{ml}$ & N/A & $1.5 \mathrm{~g}$ & $0.05 \mathrm{~g}$ & $15 \mu \mathrm{l}(12 \mathrm{M})$ \\
\hline (8) $3 \%$ agar powder $-\mathrm{pH} 3.0$ & $50 \mathrm{ml}$ & N/A & $1.5 \mathrm{~g}$ & $0.05 \mathrm{~g}$ & $34 \mu \mathrm{l}(12 \mathrm{M})$ \\
\hline (9) $3 \%$ agar powder-pH 2.4 & $50 \mathrm{ml}$ & N/A & $1.5 \mathrm{~g}$ & $0.05 \mathrm{~g}$ & $100 \mu \mathrm{l}(12 \mathrm{M})$ \\
\hline
\end{tabular}

${ }^{a}$ Mermaid, Bangkok, Thailand

${ }^{\mathrm{b}}$ Ponceau 4R, Mibo, Sabah, Malaysia

${ }^{\mathrm{c}}$ Hydrochloric acid (37\%, 16 M, MERCK, NJ, USA) 
the agar gel powder (Mermaid, Bangkok, Thailand) (2\% of the water volume) and red food dye (Ponceau 4R, Mibo, Sabah, Malaysia) $(0.1 \%)$ into $50 \mathrm{ml}$ distilled water. The mixture was heated on a hot plate until it boiled. Subsequently, the mixture was poured into a glass petri dish for cooling and hardening. The hardened mixture were then cut into uniform pellet size (approximately $2 \mathrm{~mm} \times 2 \mathrm{~mm} \times 2 \mathrm{~mm}$ ) and stored in a refrigerator $\left(4^{\circ} \mathrm{C}\right)$ until further use (Lim et al. 2015, 2016, 2017).

For preparing the FT pellet, the distilled water was replaced by the commercial pellet (Otohime EP3) extract. The extract was obtained by soaking $30 \mathrm{~g}$ of the pellet (Otohime EP3) in $100 \mathrm{ml}$ distilled water for approximately $15 \mathrm{~min}$ with occasional hand-stirring. When the water color turned dark brown, the homogenate was then filtered through a $60 \mu \mathrm{m}$ mesh net to obtain the aqueous extract. The extract was prepared only prior to the preparation of the FT pellet to maintain its freshness.

To prepare the TS pellets with different $\mathrm{pH}$ levels, various amounts of $\mathrm{HCl}$ which were preliminary determined (see Table 1) were added into the mixture (distilled water + agar gel powder + red food dye) after the mixture was boiled. In total, eight types of TS pellet with pH levels of 2.4, 3.0, 3.2, 3.4, 4.1, 4.9, 5.1, and 5.9 (the PAG) were prepared. The $\mathrm{pH}$ levels of the TS pellets were determined following the method by Sathe (1999). In brief, a few pieces of agar gel pellet from each treatment were dropped in $100 \mathrm{ml}$ distilled water, crushed with spatula, and the mixture was stirred frequently for about 3 min then the measurement was done using a pH meter (Oakton EcoTestr ${ }^{\circledR} \mathrm{pH} 2$, Eutech Instruments, Singapore). As the TS pellets with the extremely low $\mathrm{pH}$ levels ( $\mathrm{pH} 2.4$ and 3.0) could not harden naturally like the others, 3\% of agar gel powder (instead of $2 \%$ ) was used to prepare these TS pellets. To confirm that such act will not cause any bias to the results, the TS pellet with $\mathrm{pH} 3.2$ was prepared with 2 and 3\% agar gel powder and fed to the fish for comparison.

\section{Experimental fish}

Fifty Otohime pellet-trained $O$. marmorata juveniles (total length $=6.0-7.7 \mathrm{~cm}$ ) was obtained and transferred from the fish hatchery to the wet laboratory of Borneo Marine Research Institute (BMRI), Universiti Malaysia Sabah (UMS). Each individual of fish was stocked in 7-L acrylic-made aquaria supplied with 4-L water and aeration, and this was done in replicate. Before the behavioral test started, all the fish were conditioned to accept agar gel pellet using the FT pellet. The fish conditioning protocol was the same as described by Lim et al. $(2016,2017)$. Each individual of fish was conditioned once daily at 04:00 p.m. with three pieces of FT pellet. If the fish ingested the FT pellets, they were rewarded with the commercial pellet (Otohime EP3) at the end of the daily conditioning session. The fish were starved on that day if none of the FT pellet given were ingested, and the conditioning continued on the next day. The fish were considered well-conditioned and ready for the behavioral test when it accepted all three FT pellets continuously for 3 days. In the present study, all fish were successfully conditioned to accept the FT pellets within 16 days and no mortality occurred. All experimental fish were cared and handled following the Researcher's Guideline on Code of Practice for the Care and Use of Animals for Scientific Purposes, implemented by the Universiti Malaysia Sabah (UMS).

\section{Behavioural assays}

The procedures of the behavioral test used in the present study were adopted from Lim et al. (2016, 2017). The test was started at 04:00 p.m. daily. Each fish was first fed with a FT pellet to stimulate its desire to feed, followed by a TS pellet, and then another FT pellet. The final piece of FT pellet was served to remind the fish that agar gel pellet was palatable, in case the TS pellet given was a deterrent to them. During the test, feeding responses (ingestion or rejection of the TS pellet given) were examined through naked eye and manually recorded. Each treatment of TS pellet was given only once to each fish, and only one treatment of TS pellet was tested daily. At the end of the daily test, each fish was fed with three commercial pellets (Otohime EP3) as the reward to compensate its nutritional requirement. Feces and the uneaten feed in all aquariums were syphoned out and about $20 \%$ of water was exchanged on the next day morning. The cleaning and water exchanging work was done daily at least $4 \mathrm{~h}$ before the behavioral test started to prevent the fish from stress. The behavioral test was conducted under indoor condition. During the test, the water temperature was at about $28{ }^{\circ} \mathrm{C}$. The water $\mathrm{pH}$ before and after the test was at about 8.0-8.1. 
Data collection and analysis

The total number of the ingested TS pellet from each $\mathrm{pH}$ level treatment was counted. Then, the ingestion ratio [total number of the ingested pellet/(total number of the given pellet, which was 50) $\times 100 \%$ ] was calculated and expressed as the representative data. As binary data (ingested or rejected) was collected in the present study, the one-tailed binomial test was used to determine the significance of difference among the treatments. The $95 \%$ confidence interval (CI) of the total ingestion of each pH level of TS pellet was calculated and the ranges in the values were compared to each other. Significant difference $(P<0.05)$ was assumed if the range of the CI values between two treatments was not overlapped and vice versa (Sauro and Lewis 2012).

\section{Results and discussion}

In the present study, the ingestion ratio of TS pellets by the $O$. marmorata juveniles was clearly affected by the TS pellet's $\mathrm{pH}$ level. The ingestion ratio increased when the $\mathrm{pH}$ level decreased, suggesting a negative relationship between the ingestion ratio and the $\mathrm{pH}$ level of TS pellet. Figure 1 shows the ingestion ratio of the TS pellets by the juvenile $O$. marmorata. The highest ingestion ratio was found in the TS pellet with $\mathrm{pH} 2.4$ (ingestion ratio 94\%), following by $\mathrm{pH} 3(85 \%), \mathrm{pH} 3.2$ (3\% agar gel powder; 65\%), $\mathrm{pH} 3.2$ (2\% agar gel powder; 58\%), pH $3.4(24 \%), \mathrm{pH} 4.1(6 \%), \mathrm{pH} 4.9(6 \%), \mathrm{pH} 5.1(6 \%)$, and $\mathrm{pH} 5.9(2 \%)$. These results evidenced that the $O$. marmorata indeed has taste preference for food $\mathrm{pH}$ and they preferred the acidic food. In addition, no significant difference $(P>0.05)$ was observed between the ingestion ratio of TS pellets at $\mathrm{pH} 3.2$ with 2 and 3\% of agar gel powder. This result confirmed that the high ingestion ratio of the TS pellets with $\mathrm{pH}$ 2.4 and 3.0 was not due to the pellet's texture. In fact, many fish species were also reported to prefer the acidic food, including Tilapia zilli (Adams et al. 1988), European grayling Thymallus thymallus (Kasumyan 1997), tench Tinca tinca (Kasumyan and Prokopova 2001) and most of the salmonids and poecilids (Kasumyan and Døving 2003). On the other hand, acidified foods have also been reported to evoke negative response in many fish species including the puffer Fugu pardalis (Hidaka et al. 1978), acipenserids and many cyprinids (see Kasumyan and Døving 2003). Erteken and Nezaki (2002) also reported that the favorable food pH for the Black Sea turbot Psetta maxima was in the range of 7.2-7.4. Therefore, results of the present study were in agreement with the findings of Kasumyan and Døving (2003) that fish can sense sour taste and their taste preference for $\mathrm{pH}$ of the food is species-specific.

According to Kasumyan and Døving (2003), the classical taste substances that contained $\mathrm{Cl}^{-}$ion such as sodium chloride $(\mathrm{NaCl})$ and calcium chloride $(\mathrm{CaCl})$ could act as the feeding stimulant for some fish species. In the present study, $\mathrm{HCl}$ was used to adjust the $\mathrm{pH}$ level of the TS pellets. When the amount of $\mathrm{HCl}$ added to

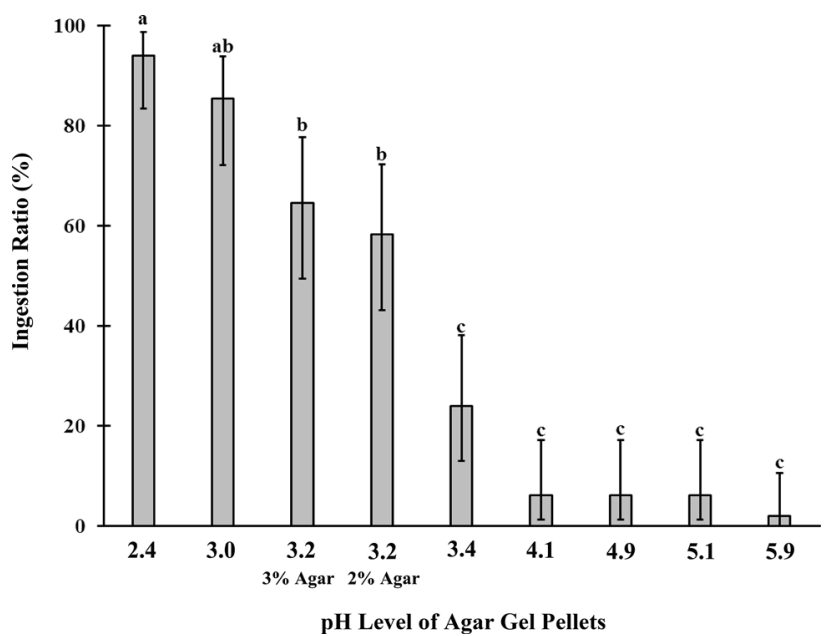

Fig. 1 Ingestion ratio of the agar gel pellets with different $\mathrm{pH}$ levels by the $O$. marmorata juveniles. Vertical bars show the $95 \%$ confidence interval of the data 
the TS pellets increased ( $\mathrm{pH}$ level decreased), the amount of $\mathrm{Cl}^{-}$ion was also increased. Fish intraoral taste system can be sensitive to the $\mathrm{Cl}^{-}$ion as examined electro-physiologically (Konishi and Niwa 1964). Therefore, the high ingestion ratio of the highly acidic TS pellets in the present study also could be contributed by the $\mathrm{Cl}^{-}$ion. However, such hypothesis could not have the vigor of the experimental trials because $\mathrm{NaCl}$ and $\mathrm{CaCl}$ were also reported as the taste-indifferent substance for many fish species (Kasumyan and Døving 2003), including O. marmorata (Lim et al. 2017).

\section{Conclusions}

In conclusion, the preference of $O$. marmorata juveniles for acidic food was confirmed, and the food's $\mathrm{pH}$ preferred by the fish was in the range of 2.4-3.0. Evaluation of the weaning performance of 0 . marmorata juveniles with the $\mathrm{HCl}$-acidified feed is recommended in a future study.

Acknowledgements This study was funded by the Research Acculturation Grant Scheme (RAGS) RAG0064-STWN-2015 from the Ministry of Higher Education of Malaysia. The authors thank Prof. Dr. Saleem Mustafa for reviewing this manuscript.

Author contributions C-FT provided ideas to refine the experimental methods, conducted the experiments, collected and analyzed the data, and wrote the manuscript. L-SL contributed the original idea of this study, designed the experimental methods, supervised the experimental data collection and analysis, and revised the manuscript. GK involved in designing the statistical analysis and proof-read the manuscript.

\section{Compliance with ethical standards}

Conflict of interest No competing interests.

Open Access This article is distributed under the terms of the Creative Commons Attribution 4.0 International License (http:// creativecommons.org/licenses/by/4.0/), which permits unrestricted use, distribution, and reproduction in any medium, provided you give appropriate credit to the original author(s) and the source, provide a link to the Creative Commons license, and indicate if changes were made.

\section{References}

Adams MA, Johnsen PB, Zhou H (1988) Chemical enhancement of feeding for the herbivorous fish Tilapia zillii. Aquaculture 72:95-107

Asia-Pacific Fishery Commission (2014) Regional Overview of Aquaculture Trends in the Asia Pacific Region 2014. RAP Publication 2014/26. Food and Agriculture Organization of the United Nations (FAO), Bangkok, Thailand

Cheah SH, Senoo S, Lam SY, Ang KJ (1994) Aquaculture of a high-value freshwater fish in Malaysia: the marble or sand goby (Oxyeleotris marmorata, Bleeker). Naga ICLARM Q 17:22-25

Erteken A, Nezaki G (2002) Effects of feeding stimulants, and diet pH on the growth of Black Sea turbot, Psetta maxima. Turk J Fish Aquat Sci 2:19-22

Hidaka I, Ohsugi T, Kubomatsu T (1978) Taste receptor stimulation and feeding Behaviour in the puffer, Fugu pardalis I. Effect of single chemicals. Chem Sense Flavor 3:341-354

Kasumyan AO (1997) Gustatory reception and feeding behavior in fish. J Ichthyol 37:72-86

Kasumyan AO, Døving KB (2003) Taste preferences in fish. Fish Fish 4:289-347

Kasumyan AO, Prokopova OM (2001) Taste preferences and the dynamics of behavioural taste response in the tench, Tinca tinca (Cyprinidae). J Ichthyol 41:640-653

Konishi J, Niwa H (1964) Some properties of taste receptors in freshwater fish: responses to weak solutions. Jpn J Physiol 14:328-343

Lai SKJ, Lim LS, Yong ASK, Kawamura G, Shapawi R (in press) A preliminary study to determine the potential of a prototype feeding stimulant in improving the weaning of juvenile marble goby (Oxyeleotris marmoratus). Songklanakarin J Sci Technol

Lim LS, Lai JSK, Yong ASK, Shapawi R, Kawamura G (2015) A preliminary study on the taste preference of marble goby (Oxyeleotris marmoratus) for amino acids. Songklanakarin J Sci Technol 34(4):397-400

Lim LS, Lai JSK, Yong ASK, Shapawi R, Kawamura G (2016) Evaluation on the potential of betaine, taurine, nucleotide and nucleoside as feeding stimulant for juvenile marble goby Oxyeleotris marmoratus through behavioural assays. Int Aquat Res 8:161-167

Lim LS, Lai SKJ, Yong ASK, Shapawi R, Kawamura G (2017) Feeding response of marble goby (Oxyeleotris marmorata) to organic acids, amino acids, sugars and some classical taste substances. Appl Anim Behav Sci 196:113-118 
Lin CK, Kaewpaitoon K (2000) An overview of freshwater cage culture in Thailand. In: Liao IC, Lin CK (eds) Proceedings of the First International Symposium on Cage Aquaculture in Asia, May 2000. Asian Fisheries Society, Manila, Philippine, pp 253-257

Luong VC, Yi Y, Lin CK (2005) Cove culture of marble goby (Oxyeleotris marmorata Bleeker) and carps in Tri An reservoir of Vietnam. Aquaculture 244:97-107

Rojtinnakorn J, Rittiplang S, Tongsiri S, Chaibu P (2012) Tumeric extract inducing growth biomarker in sand goby (Oxyeleotris marmoratus). In: Proceedings of the 2nd International Conference on Chemical, Biological and Environment Sciences (ICCEBS 2012), Bali, June-July, 2012. Planetary Scientific Research Centre, pp 41-43

Sathe AY (1999) A first course in food analysis. New Age International (P) Limited Publishers, New Delhi

Sauro J, Lewis JR (2012) Quantifying the user experience: practical statistics for user research. Morgan Kaufmann (MK) Publishers, Waltham

Yong ASK, Ooi SY, Shapawi R, Biswas AK, Kenji T (2015) Effects of dietary lipid increments on growth performance, feed utilization, carcass composition and intraperitoneal fat of marble goby, Oxyeleotris marmorata, juveniles. Turk J Fish Aquat Sci 15:653-660

\section{Publisher's Note}

Springer Nature remains neutral with regard to urisdictional claims in published maps and institutional affiliations. 